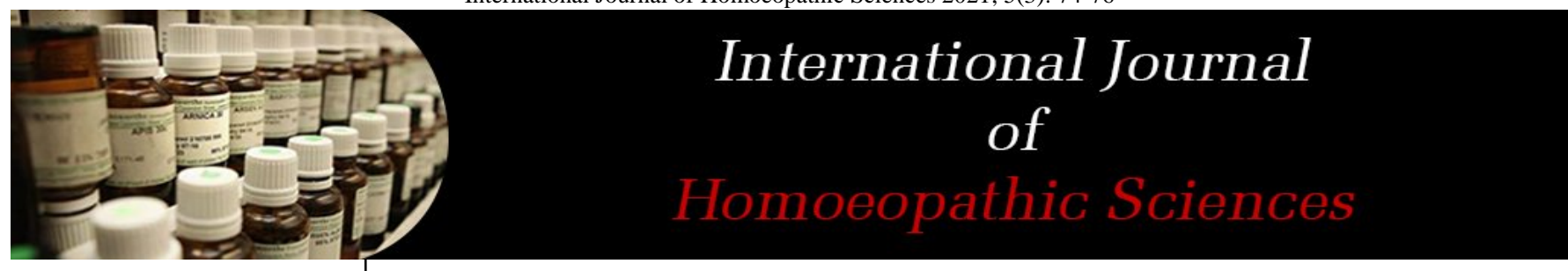

E-ISSN: 2616-4493 P-ISSN: 2616-4485 www.homoeopathicjournal.com IJHS 2021; 5(3): 74-76

Received: 12-04-202

Accepted: 10-06-2021

Dr. Rohit Kumar

PG Scholar, Department of Md Homoepathy (Repertory), Shri Guru Nanak Dev

Homoeopathic Medical College and Hospital, Ludhiana Punjab, India
Corresponding Author: Dr. Rohit Kumar

PG Scholar, Department of Md Homoepathy (Repertory), Shri Guru Nanak Dev

Homoeopathic Medical College and Hospital, Ludhiana Punjab, India

\section{Obesity and its homoeopathic management}

\section{Dr. Rohit Kumar}

DOI: https://doi.org/10.33545/26164485.2021.v5.i3b.407

\section{Abstract}

Over-weight and obesity represent a rapidly growing threat to the health of population in an increasing number of nations. Indeed, these are now so common that they're replacing more traditional problems like under nutrition and infectious diseases because the most vital causes of unhealthiness. Obesity are often seen because the first wave of defined clusters of non-communicable diseases, now observed in both developed and developing countries.

Keywords: Obesity homeopathic treatment, management, life style disease

\section{Introduction \\ Definition}

Obesity is defined as a condition of abnormal or excessive fat accumulation in fat to the extent that health may beimpaired ${ }^{[1]}$.

Hypertrophic obesity-thanks to increase in adipose cell size. Hyperplastic obesity-thanks to increase in adipose cell number. In early onset obesity, there's both hypertrophy and hyperplasia; but in late onset obesity, only hypertrophy is seen. Obesity is defined as an accumulation of body fat quite $22 \%$ of the entire weight for men and quite $30 \%$ of total weight for women ${ }^{[2]}$.

\section{Factors associated with idiopathic obesity}

Age: A Critical periods for the event of obesity.

Prenatal: Nutrition during fetal life may contribute on to the event of the dimensions, shape and composition of the body, and to the metabolic competence to handle macronutrients. Close relationships exist between patterns of intra uterine growth and therefore the risk of abdominal fatness, obesity and their co-morbidities in later life ${ }^{[4]}$.

Infancy: Most studies of infant size found that infants who were defined as obese or who were at the upper end of the distribution of weight or BMI were more likely to develop obesity in childhood, adolescence or early adulthood than other infants ${ }^{[5]}$.

Adiposity rebound period: 5 to 7 years. BMI begins to increase rapidly after a period of reduced adiposity during the pre-school years. This period coincides with increased autonomy andsocialization ${ }^{[5]}$.

Adolescence: A period of increased autonomy often associated with irregular meals, changing food habits and periods of inactivity during leisure. The risk of obesity persisting in to adulthood is higher among obese adolescents than among younger children ${ }^{[6]}$.

Early adulthood: Is usually a period of marked reduction in physical activity. In women this usually occurs between 15 to19 years; but in men, it may be as late as early 30's ${ }^{[6]}$.

Pregnancy: It's been claimed that a mother's BMI increases with successive pregnancy. Many study designs confound that changes in weight occur with ageing and parity, but in many developing countries consecutive pregnancies at short interval are often related to weight loss instead of with weight gain.

Birth weight: Many studies showed a direct relationship between birth weight and later BMI. Data reported by Bavdekar et al. related birth weight in 250 gm groupings between 2.0 
$\mathrm{kg}$ and $>3.25 \mathrm{~kg}$ to BMI at 8yrs of age. Mean BMI increased linearly from 13 to 14.1 across these birth weight groups. But a few studies have shown higher prevalence of obesity in low birth weight groups.

Sex: A number of physiological processes are believed to contribute to an increased storage of fat in females, such as fat deposits are believed to be essential in ensuring female reproductive capacity. Females have a tendency to channel extra energy in to fat storage ${ }^{[7]}$.

Socio economic status: may dictate lifestyle behavior that end in increased risk of childhood obesity. Low-income family may face lack of safe place for physical activity, lack of consistent access to healthy food choices particularly fruits and vegetables ${ }^{[7]}$.

\section{Causes of childhood obesity \\ Genetic/Familial}

1. Environmental: Decreased activity, increased calorie intake, TV viewing, video games and computer games.

2. Endocrine: Hypothyroidism, Cushing syndrome, Hyperinsulinism, Pseudo-hypo parathyroidism, Hyperandrogenism, somatotropin deficiency and purchased hypothalamiclesions.

3. Genetic syndromes: Prader Willi syndrome, Lawrence Moon Biedel syndrome, Carpenter syndrome, Turner syndrome, Klinefelter's syndrome.

4. CNS lesions: Infections, trauma, surgeries, irradiation, Craniopharengioma.

5. Drugs: Steroids: Glucocorticoids and Progesterone, Antipsycotic medications: Clozapine, Olanzapine, Antidepressant drugs (SSRI): Fluoxetine, Paroxetin Miscellaneous- Leptin deficiency and MC4R deficiency ${ }^{[5]}$.

\section{Pathogenesis}

Genetics: obesity may be a truly complex multi factorial phenotype with a genetic component that has both poly genes and major gene defects. Over 70 genes are identified to be associated with obesity. When these genes are exposed to adverse environment, obesity develops. Recent studies have shown that the quantity of abdominal fat was influenced by the genetic components accounting for 50 $60 \%$ of the individual differences ${ }^{[3]}$.

\section{Types of genetic defects}

Genes exert their influence on body mass and body fat, either in the coding sequence of the genes or in the segments that affect gene expression.

The genetic susceptibility seem to be either caused by genes associated with an increase in the susceptibility to gain weight over time or by the absence of genetic influences that protect against the development of positive energy balance $^{[9]}$.

\section{Measurement of obesity}

Body mass index (BMI) is taken into account to supply the foremost useful 'albeit crude population' measure of obesity. BMI may be a useful index to assess overweight, and may be a fairly reliable surrogate for adiposity ${ }^{[3]}$. BMI correlates ( $>0.8$ ), with body fat as determined by both skin fold thickness measurement and by densitometry with an accuracy of up to 0.8 decibel. Thus, it's an inexpensive criterion for determining obesity in children and adolescents [4]. BMI also correlates with markers of secondary complications of obesity including current blood pressures, blood lipids, and with long-term mortality ${ }^{[4]}$.

\section{Limitations of BMI}

1. It cannot differentiate between obese individual from a muscular individual with high BMI.

2. It cannot locate the site of adipose tissue.

3. It may not consider individuals with central obesity as obese at all ${ }^{[7]}$.

\section{Factors affecting BMI}

Age, gender and puberty may introduce another change in weight for height relationship.

\section{Authors saying about obesity and homoeopathy}

In Hahnemann's words, "The true natural chronic diseases are those that arise from a chronic miasm, when left to themselves, improper treatment, go on to increase, growing worse and torment the patient to the end of his life." - 78 Organon Hahnemann spent 12 years of his life investigating miasms, collecting proof these findings going unnoticed by others in the medical professions, "the chronic diseases" was written. He describes how using antipsoric medicines used on the psora miasm would enable a practitioner to cureeffectively ${ }^{[12]}$.

The conditions that would modify a miasm in a person's body would be things like, climate and peculiar and physical character of the person it is in, mental delays, excesses, or abuses in life, in diet passions, habits and various customs. Disease is a state including disharmonious functioning of the life force. We become aware of this disharmony by the loss of that sense of well being which we have learnt to accept as normal.

\section{Therapeutics on obesity}

\section{The commonly used drugs are}

- Drugs in potencies e.g. calc. carb, graph, caps, ferr met, etc.

- Drugs in trituration e.g. phytolacca berry, fucus, thyroidinum, etc.

- Drugs in crude form: e.g. phytolacca, fucus, etc.

- Antim crud: Tendency to grow fat, obese people with thickly coated tongue and digestive disturbances of varying degrees. The constitutions are very irritable and fretful.

- Calcarea carb: Suitable for women and children of leucophlegmatic temperament with tendency to obesity. Constitutions deficient in assimilative powers are benefited by this remedy. Rapid deposit of fat in cellular tissues, especially around abdomen but tissues is imperfectly nourished ${ }^{[16]}$.

- Capsicum: Suited to persons who are fat, indolent, opposed to physical exertion, get homesick easily. Persons having feeble digestion and lax fiber. Chilly subjects with lack of vital heat.

- Ferr met: Flabby, anemic and plethoric persons with false plethora and relaxed muscles. Easily irritable constitutions having voracious appetite. 
- Fucus vesiculosis: Obesity associated with non-toxic goitre with flatulent tendency and obstinate constipation. This remedy is used in material doses and triturated preparations.

- Phytolacca berry: Clinically found to be efficacious in obesity ${ }^{[13]}$.

\section{Discussion}

Obesity in childhood and adolescents is one of the foremost common problems. The results of management by various system of medication aren't satisfactory. Hence Homoeopathic system has been approached and treated accordingly.

\section{Conclusion}

Homoeopathic medicines beside the management area unit found to be extremely efficacious at intervals the management and treatment of blubber, as majority variety of patients was found to boost. This was a modest effort on my half to grasp the role of homeopathy at intervals the management of blubber in childhood and adolescent victimisation repertory of homoeopathic material medica by J.T KENT and thus the study is type of satisfactory.

\section{References}

1. Kliegman, Behrman, Jenson, Stanton, Nelson Text Book of Pediatrics. Vol II., Published by Elselier India Publications, $18^{\text {th }}$ Edition 2008, 232pp.

2. Ghai OP, Piyush Gupta, Paul VK. Ghai Essential Pediatrics, New Delhi; Published by CBS Publishers \& Distributors, Reprint Edition 2005, 116pp, 118pp.

3. Harrison. Principles of Internal Medicine, International Edition 2001, 479pp, 480pp.

4. API. Text Book of Medicine, Mumbai; Published by Association of Physicians of India, $5^{\text {th }}$ Edition 1992, 261pp, 262pp, 288pp,

5. Lawrence Tierney, Jr. Stephen Mcphee J. Current Medical Diagnosis \& Treatment, International Edition 2001, 123pp, 124pp

6. Hager A. British Medical Bulletin 1981;37(3):287.

7. Shetty PS. Childhood obesity in developing societies. NFI bulletin 1999, 1-4.

8. Unhealthy school children. Lancet 1999, 351-2133.

9. Chatterjee P. India sees parallel rise in malnutrition and obesity. Lancet 2002;360:1948.

10. Kent JT. Lectures on Materia Medica. Reprint Edition, New Delhi; B. Jain Publishers Pvt. Ltd, 2002, 311pp, 526pp

11. Kent JT. Repertory of the Homoeopathic Materia Medica and a Word Index.

12. Reprinted. New Delhi: B. Jain Publishers (P) Ltd 2001, 9pp, 12-14pp, 36-39pp, 48-51pp, 64pp, 68-89pp, 477486pp, 775pp, 1062-1107pp, 1251-1298pp, 1348pp, 1372pp, 1402pp.

13. Hahnemannian Totality Symposium Part-I Area-C: Perceiving: Miasmatic Evolution, Published By Dr. M.L. Dhawale Memorial Trust, 3 rd, Edition Published at Mumbai Editer Dr. M.L. Dhawale 2003, 30pp, 33pp.

14. Kent James T. Lesser Writings, New Delhi, B.Jain Publishers Ltd Reprint Edition 1992, 53pp, 54pp.

15. Allen JH. The chronic miasms. Reprinted New Delhi: B. Jain Publishers Pvt. Ltd. 1998, 55pp.

16. Hahnemann Samuel. Organon of Medicine, $6^{\text {th }}$ Reprint Edition, B. Jain Publishers, New Delhi 1996, 21pp. 